\title{
CONSIDERATIONS ABOUT LABOR MARKET IN ROMANIA - THE MARKET OF EDUCATIONAL SERVICES -
}

\author{
Ph.D. Professor MAN Mariana \\ The Petroşani University \\ Ph.D. Assistant professor MIHÄESCU Liviu \\ "Lucian Blaga" University of Sibiu
}

\begin{abstract}
The paperwork discuss about the specific argument brought against encouraging the market's mechanisms in the field of education, who send to the unity's imperative, the educational system's coherence, because the market's mechanisms are by their nature autonomic and a trade market including the educational market, functions better when the number of agents is larger, with equal powers and separated by one another, more autonomic. Any interfering or any mechanism of shaking the autonomy leads to narrowing the market's laws area of action and encouraging the market's mechanism leads to an educational system's decentralization.
\end{abstract}

Our research in Romania is based on the data during the period 2000- 2006 using the following theoretical concepts:

The mechanisms of the market of educational services

The problem is not about accepting or not the existence of a market of educational services, the market's mechanism was developed and they can not be ignored any more. But remains the problem of having the best approach in front of the education market's phenomena, and how and if we should stimulate or stop the mechanism which sometimes are not very genteel nor proffitable which usually accompany the development of a educational service market, having not only scientifically and technical components but attitudinal elements too, having in view the nature of interest and the value options. The dilemma is how much we have to control the phenomena which appear on the education market but also how much we should control this phenomena which often have a natural way of developing which slip our power of interfering. We have to discuss how much it is allowed to manipulate the natural trend of educational offer and demand, as long as education it still remains an activity associated with the human individual attributes (liberty, dignity, responsibility).

First and the most used argument by consumers against the mercantile phenomena, but also of the idea of market in education, is of moral and philosophical structure and it accuses the mercantile phenomena which could appear in one field which it is or should be lead by noble goals and moral values.

The arguments against encouraging the market's mechanisms in education come from different direction - equal opportunities, and its positive effects of applying this can not be ignored. Therefore the almost general process of democratization of the education system was based on this principle. We should mention that the principle of equal opportunities was adopted by all educational systems from the former socialists countries, but not as a loan or as an 
convergent element with the decadent capitalism, but as a fundamental criteria of qualitative dissociation of the socialist system.

The problem of the unitary character of the educational system and the risk of disintegrating the systems through encouraging the necessary autonomy in a market of educational services it becomes more complicated if we take into consideration all the consequences that follow up every process of decentralization.

In this context, in Romania, in time established two of the controverter trends of the educational system: the exceptional performance to coexist with the mediocrity in a mass proportion; an educational system which is considered to be of high performance to be accompanied year after year by an uncompetitive economy, of low quality and structural very rigid, which became step by step incapable of sustaining and absorbing the high performance;

\section{$>$ The market concept of the educational services}

The starting idea on which we based our study is that the market of educational system exists and behind having an attitude the only rational approach is to recognize its existence and to try to see all the details and mechanisms through which constitutes itself and through which forces the social agent's actions, directly on indirectly, on this market. But just like any other social phenomena, the educational services market it is not only a perceptible reality or identifiable at the level of the market's specific indicators but a social representation too, a mental object, a pattern, a mechanism through which theories were built about the social environment, a way of thinking the context practical, a way of behaving, a filter, a screen between the pressure of social and the personality's system.

In this context we should analyze three problems of the educational services market:

- Who are the agents which interacts on this market?

- Which is the market's objective?

- How is manifested the demand, offer and competition on the educational services market?

\section{$>$ The object of the educational services market}

Identifying the object of the educational services market it seams to be an easy job which can be fulfilled by applying the economic algorithm, and this algorithm says that the market's object consists in the economic goods (off course we refer at the goods market and not at the financial market) The economic goods are defined by comparing with the free goods. In contrast with the free goods, which are a gift from nature, (air, solar light, etc.) were we have free access, the economic goods - in their largest meaning, including both material goods and services and information- are the result of a production process which implies effort and expenses. The main distinctive note for the economic goods is the rarity, because they are always limited an insufficient reported to the needs.

If we take into consideration that education is an activity which implies effort and expenses, then the education process can be treated as analog with the economic goods - specific economic goods which could be considered as educational goods.

If we take into consideration the term of economic goods, including not only the material goods but the services and information too, then the term educational goods could be considered an appropriate term to define the educational market's object. When we talk about educational goods we talk about knowledge, skills and attitude all this are pedagogical organized by school transmitted through the training process in order to be learned by its direct beneficiary (students) and to be used by them for a good social and professional integration. Obviously the term 
educational goods has no meaning if the school doesn't fulfill all the steps of its actions, emphasizing the last two steps (assimilation and use).

The educational chain is a construction based on the approach of the educational process as an open and interconnected system, in which every element has different intensities, and the chain's elements frames the educational process steps and contains five levels: preschool education, basic school education (first 9-10 school years), general education (the last 2-3 school years)and professional training, higher education (university), permanent education. Every step of the process is defined on the bases of its functions and its specific results of the educational process at the level.

$>$ The relation between the public / private character of the educational services and the public/ private character of the university's human capital.

The costs of the educational services are paid the direct or indirect beneficiary, the use of higher education it is obvious. The persons who pay for their education generate positive external effects which are not compensated neither financial (the higher education graduates who pay taxes do not receive a higher income then the other graduates which do not pay), nor on indirect ways (the society doesn't value more the graduates who paid their education).

In the case of public education services or more exact, financed from the state budget, the situation changes radically, because, the private income generated by the university's human capital are larger then the social incomes. And all this because the private income of the owners of educational capital are pure incomes and on the other hand the public incomes are obtained with expenses, more clear, the income is estimated after the expenses were paid. In this situation we can talk about a negative externalization of education, in the sense that the society represented by the state- it is not rewarded neither for the produced positive effects nor for the endured negative effects. In this context the statement that the owner of the university human resources which acquired the resources through study programs financed from the state's budget and they leave the country is the direct carrier of a capital leakage, and the emigration country is the beneficiary of its educational capital at a lower price and the country from which they emigrate it is forced to reproduce this capital at a higher price than the normal one - the situation can be considered as illustrative for the negative externalization phenomena of education and especially for the higher education, having in view the fact that the process is financed from the state budget;

\section{$>$ The educational activity market's actors}

The economic science has a large variety of market's definitions, each one emphasizing certain elements and /or certain processes which form the market's complex phenomena. from all this we will use one classic definition which sustain that the market is the place where economic agents meet being divided into two big categories: buyer and salespeople bur we have to mention that on the same market and in the same action of trade an agent can have only one quality, either sales or buys.

On the market of educational services and goods when they have a public character things get more complicated: the educational goods and services are not always bought (sometimes they are obtained for free), the buyer always names the consumer but he has to be one way or the other the beneficiary of the bought goods etc. Therefore we have at least two questions:

- Can we talk about buying, in the strict sense of the term, in the case of educational goods and services?

- If yes, who are the agents who enter on the market as buyers? 
We have the same problems when we try to define the salesman qualities, for the paid educational process, is it the institution which offer education in change of a tax and sales its services to some buyers, very easy to identify, for a tuition fee. For the tax free education programs, the quality of salesman is not so obvious, the organizations appear more as the one who offer and not as salesmen and they can be considered more as intermediary agents, salesman- buyer but first it buys the educational services and then he re-sales, are given free of charge to its citizens. If we have in view the main income source which come from the state budget for financing education (taxes collected from the citizens), the buyer should be considered to be a citizen who pays taxes even if it doesn't decide the price and the quality of the goods and the way this product it is used.

Having in view the theory the research was based on:

\section{$>$ The school population dynamic on educational levels}

The dynamic of school population on educational levels during 2000- 2006 (fig no.1) shows us real decline in the primary level $(2 \%)$, middle school $(1 \%)$ and high school $(4,4 \%)$ vocational school $(1,9 \%)$ while the higher education percent grew $(6,5 \%)$. The decline first of all is because the population migration to Bucharest and west regions and to the European Union countries.

Fig 1. The school population dynamic on educational levels during 2000- 2006 associated professors

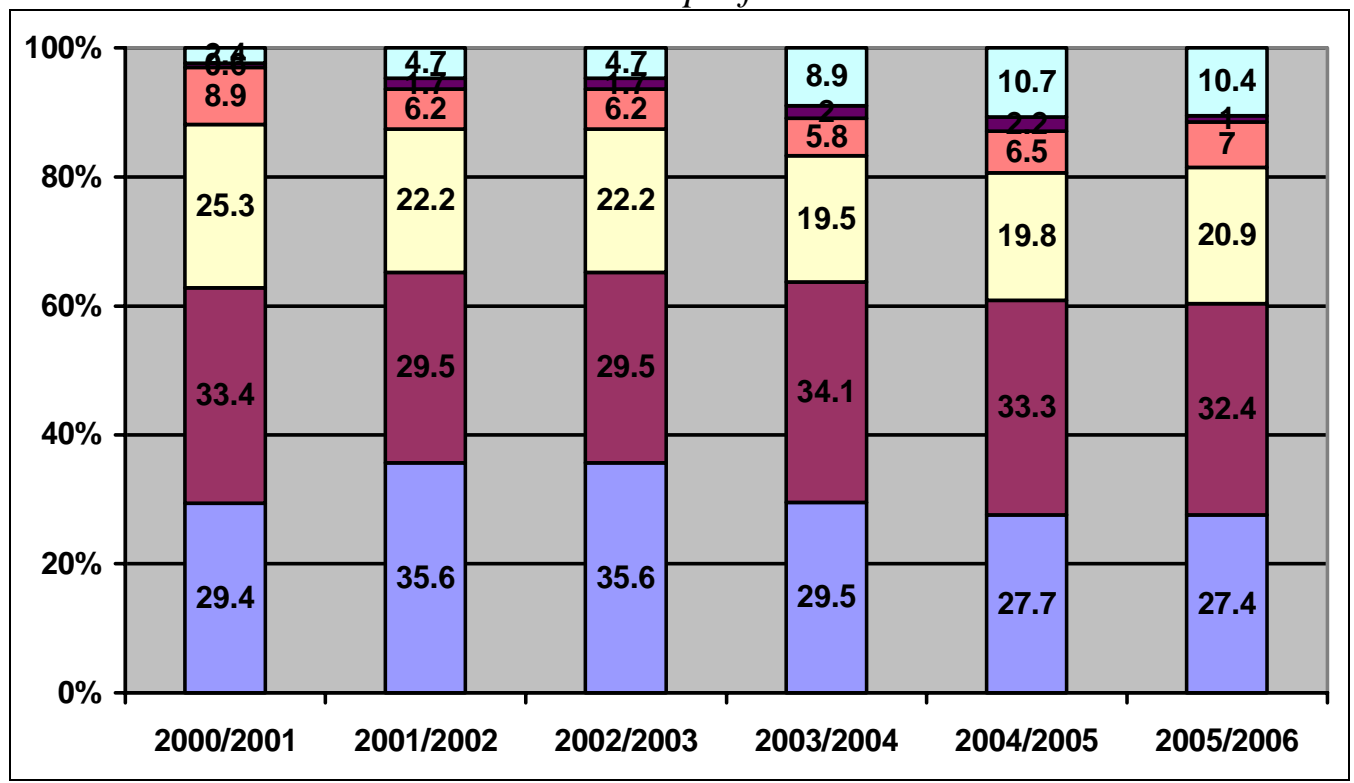

Caption: primary level, middle school, high school, vocational school

After the decrease in the period 200/2001 and 2005/2006 both as number and as total percentage of school population from the vocational education has recorded an increase which seams to be maintained in the next few years. The school population from the postgraduate highschool (both as number and as total percentage of school population) has recorded a reverse dynamic after a growth during the school year 2000/2001 was followed by a decrease;

The rate of including in the educational system 
This rate has close value with the national average rate of including in the educational system - at all the levels, primary, middle and high schools (Fig no. 2)

Fig. no. 2 The rate of including in the educational system of school population- on levels

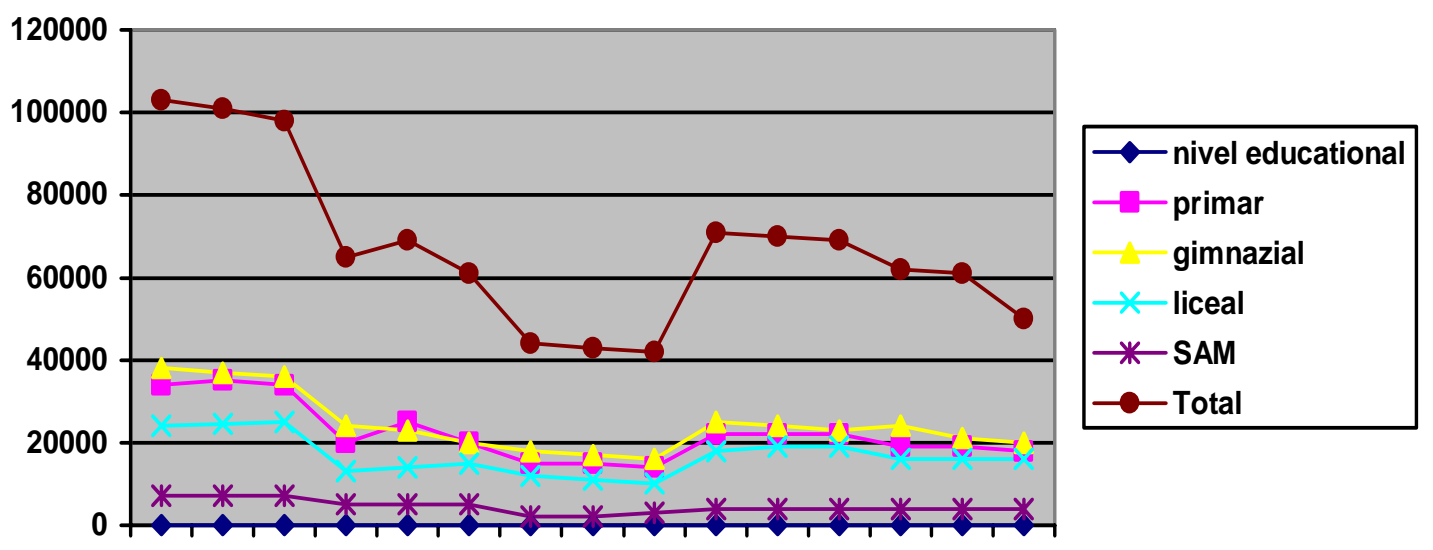

The student's participation in the technical and vocational education

At the level of the technical and vocational education (Fig. no. 3) during the school years $2000 / 2001$ and 2005/2006 the school population enclosed in this form of education recorded an important decrease.

Fig no.3 School population evolution in the vocational and technical education in the period 2000- 2006

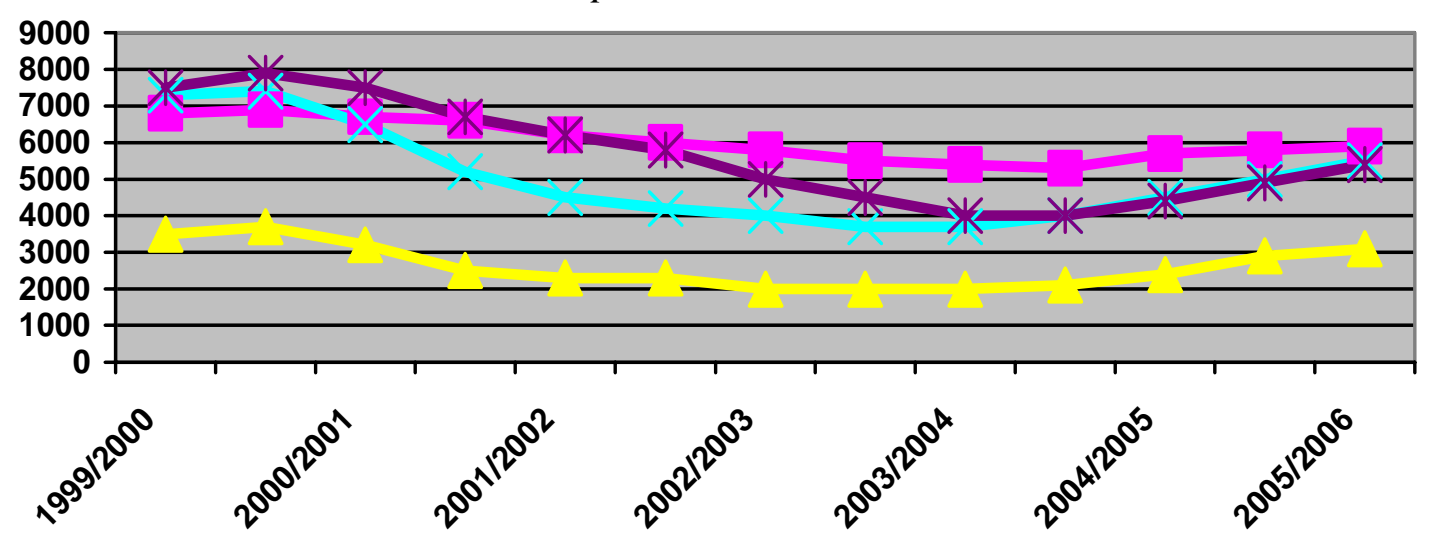

At this level we can see an increase of student's number who choose this form of training starting with the year 2000- 2001 with few decreases during the school year 2002- 2003;

The including rate of the students with special needs in TVET

A very important factor is the existence of vocational school which train students with special needs in developing different skills, increasing their chances in integrating in the labor market after graduation (Table no.1). 
Table no 1 The number of the students with special needs included in different educational levels in the period 2004- 2006

\begin{tabular}{|l|c|c|c|c|c|c|c|c|}
\hline \multirow{2}{*}{ Educational level } & \multicolumn{3}{|c|}{ School year 2004-2005 } & \multicolumn{3}{c|}{ School year 2005-2006 } \\
\cline { 2 - 10 } & Institutionalized & \multicolumn{2}{c|}{ Included } & \multicolumn{2}{|c|}{ Institutionalized } & \multicolumn{2}{c|}{ Included } \\
\cline { 2 - 9 } & Urban & Rural & Urban & Rural & Urban & Rural & Urban & Rural \\
\hline Primary School & 164 & - & 287 & 79 & 157 & - & 223 & 98 \\
\hline Gymnazium & 395 & - & 383 & 161 & 379 & - & 368 & 155 \\
\hline Theoretic High School & 2 & - & 11 & & 2 & - & 10 & - \\
\hline Technologic High School & - & - & 12 & - & - & - & 12 & - \\
\hline SAM & 171 & 152 & 231 & 25 & 200 & 129 & 256 & 17 \\
\hline Total & 732 & 152 & 924 & 265 & 738 & 129 & 869 & 270 \\
\hline
\end{tabular}

In the school year 2004-2005 students with special needs from SAM were about 2,1\% from the total number of the students enrolled at SAM, and in the school year 2005-2006 the percentage grew to 2,2\% therefore the local authorities and the local School Inspectorate showed a bigger concern in providing specific environment for this students;

\section{The including rate of the students of rom origin in TVET}

Thanks to the implementation in the educational system of some programs in order to attract and maintain the rom population into the educational system are made major efforts for including this population in the educational system. We can see a growth of the level of including the rom students in technologic high schools with $19,12 \%$ and in SAM with $28,86 \%$ in the same time with decreasing the school drop rate at both educational levels (Table no.2)

In the school year 2004-2005 the percentage of the rom students in the high school and vocational school is about of $21,5 \%$ from the total number of gymnasium students and in the school year 2005-2006 the percentage dropped with 2,7\% reaching at $18,8 \%$;

Table no.2 The number of rom students included in different levels of education in the period 2004- 2006

\begin{tabular}{|c|c|c|c|c|c|c|c|c|c|c|}
\hline \multirow[t]{3}{*}{ Educațional level } & \multicolumn{6}{|c|}{ School year 2004-2005 } & \multicolumn{4}{|c|}{ School year 2005-2006 } \\
\hline & \multicolumn{2}{|c|}{ Included } & \multicolumn{2}{|c|}{ Abandonment } & \multicolumn{2}{|c|}{ Non-promoted } & \multicolumn{2}{|c|}{ Included } & \multicolumn{2}{|c|}{ Abandonment } \\
\hline & Urban & Rural & Urban & Rural & Urbar & Rural & Urban & Rur: & Urban & Rural \\
\hline Prima & 3375 & 3296 & 186 & 122 & 84 & 100 & 3440 & 3452 & 204 & 149 \\
\hline & & 2067 & 203 & 234 & 121 & 105 & 2593 & 2670 & 226 & 186 \\
\hline & & 3 & 6 & & S & & 104 & 8 & 11 & \\
\hline Technol & 183 & 22 & 14 & 27 & 29 & 21 & 218 & 43 & 10 & 21 \\
\hline $\mathrm{AM}$ & 395 & 123 & 62 & 33 & 37 & 19 & 509 & 110 & 31 & 24 \\
\hline otal & 5726 & 5511 & 454 & 416 & 280 & 245 & 6864 & 6283 & 482 & 380 \\
\hline
\end{tabular}

\section{School abandonment rate}

As regarding the school abandonment as the analyzed data from 2004- 2006, the school drop at all educational levels is of about $0,83 \%$ and it is recorded a decrease in the school year 2004- 2005 with $0,21 \%$. In the vocational education the school drop rate is of about $2,82 \%$ in the year 2004- 2005 and 1,66\% in the school year 2005-2006; 


\section{Non- promoted rate}

Regarding the non-promoting school rate as the data provide in the period 2004-2006 at all the levels is about of 2,26\% and it is recorded a decrease in the school year 2004- 2005 with $0,12 \%$. In the vocational education the rate is of $1,85 \%$ in the year $2004-2005$ and $2,25 \%$ in the school year 2005-2006;

\section{$>$ The success rate at certificate exams for the professional skills}

At national level the percentage is of $98 \%$ for this period. In 2012 the projection of graduates is estimated at 100\%. Until 2012 the number of graduates show a decrease with long and medium term implications in decreasing the number of teaching staff and auxiliary staff and disappearing more institutions. All this aspects have to be taken into account by the organizations implicated into financing/planning: Ministry of education and research, Local School inspectorate, Local Community for resizing the school network and fond necessary in developing the education process;

The graduates situation and the school population dynamic it is very important having in view the fact that they will represent the labor market's penetration in the next few years and the enrolment level in the educational system.

The Romanian labor market suffered major changes having in view the economic changes through the decrease of the active population and the engaged population, maintaining the unemployment at a relative constant value (except the economic recession periods), but the increase of long term unemployment and the growth of inactive population.

The demographic phenomena over the human resources (drop of birth rate, high mortality rate, external migration) was followed by economic effects like: economic changes, recession which brought to an urban-rural migration and agriculture activity only for survival, the development of the informal labor market or a important rate of inactive population.

At the country's level, the inactive population from the economic point of view developed in an negative way, reaching in the year 2004 at only 1.123 thousand persons $(11,3 \%$ out of the national level)

With an activity rate of $65,2 \%$ for the active population of $15-64$ years old, Romania is found under the EU average of $69,3 \%$.

Challenging with the unemployment rate and the decrease of the engaged population, the active population evolution for the age segment 15- 64 dropped at 65,2\% in the year 2005 .

In the rural environment, the economic activity has a better rate compared to the urban environment $(69,9 \%$ and 60,8\%) for the entire active age segment, but even for the age group 15$24(46,9 \%$ and $25,8 \%)$ and $55-64$ years $(61,5 \%$ and $30,1 \%)$. This situation is the result of the migration from the city to the village of the active population of over 50 years old, and the insertion on the labor market of the young rural population.

The country's engaged population was characterized by a continuous rate of occupation this being the result of the economic decline, of some structural lack of balance, and the lack of economic performance and competitive, as well as on territory and on the labor market.

As a result of the economic change process, in some cities like Gorj and Valce, the decrease was more drastic compared to other cities where the impact was not so big like in Olt and Dolj, compared to the country's average.

On economic activities, the most important engaged population drop took place in: extract industry, hotels and restaurants, transport. 
The most important growth was recorded in the public administration, trade, financial trade and health.

Beside some structural lacks of balance, the main problem remains the high rate of engaged population in agriculture.

In industrial activities we have recorded a growth only in electric and optical equipments.

The study shows the fact that we will encounter lacks of balance on the labor market until 2013 forecasting a better offer at regional level. Will take place a decrease of the demand for the workers in some cities like Olt (with 3,2\%), Dolj (with 1,7\%) and Mehedinti (1\%) but little growth of the demand in some cities like Gorj $(1,1 \%)$, Valcea $(0,2 \%)$ etc.

On economic activities, the rhythm analyze of the workforce evolution potential demand until the year 2013 show a decrease of the demand in activities like: Agriculture, hunting, forestry, public administration and defense, education and electricity, thermal, gas, water. The economic activities with high growth potential on labor market are estimated to be: construction, trades, hotels and restaurants, transportation, storage, communication, financial trade, real estate trades and services offered by firms.

The fields with highly development perspective are services (a very important place it has social services), construction and other activities, food industry, heavy industry, electrical and optical equipment industry, hotels and restaurants, commerce, services (transportation, storage), communication, financial trades.

As a result of the lack of balance on the labor market (where the job offer is bigger than the demand) and on the goods and services (where the production is lower than the demand) we have the unemployment phenomena this phenomena being measured through 2 indicators: the unemployment as (Labor International Bureau) LBU and the recorded unemployment.

The $L B U$ number of unemployed having in view the age group and sex we can see an high percentage of unemployed females, for the age group 15-24 years old, and 19,3\% what shows us that it is more difficult for a woman to get employment.

The unemployment rate in Romania had a descendant rate with 40732 persons. The rate of unemployment at women had the same trend.

The large number of unemployed and the low level of education indicate a high need of training, which is not covered by the relative number of authorized organizations. The number of participants at the vocational programs offered by AJOFM and private trainers or the regional centers for training adults took part especially women.

There are many problems which challenge the engagement rate in this programs both the persons and trainers starting from the lack of financial support continuing with the rigid system of organizing the training programs for adults. There is not yet a functional ECTS system for the training received in formal, informal or non -formal contexts. many times the training programs are on long term, organized on modules and without giving the possibility of practice any job after being completed one or more modules.

The vulnerable groups for which is necessary to concentrate all the efforts of all the responsible factors for assuring equal chances for education and vocational training are: the rural school population, especially the one from the isolated and inaccessible areas; rrom school population; school population with special needs.

The geographical areas on which we should focus for developing alternatives of the classic forms of education are the isolated ones or the one which are found at large distance from the places where develop activities Vocational schools. The areas with a poor population, or rrom should be taken into consideration by the decisional factors and of educational partners, for 
adopting necessary measures which could lead to the enrolment of all the children for the 10 years compulsory education and to assure the easy access at TVET education.

The results of the study show that the most important fields are: construction, food industry, wood industry, electronics and services. Regarding the services and constructions are very important for the increase of the enrolment figures and reaching from the first qualification level to the second and even to the third level for the services.

For road and maritime transport it is necessary to adapt the demands to the CDL established by the international transports. In the industrial field the curricula should adapt to the labor market's demands. Here it must be reordered the structure of the initial training, growing the weight for IT field, electronic, automatization. The food industry will record a development imposed by the need of a better use of the regional agricultural products, accomplishing an important absorption of the labor force. 